\title{
Understanding Uncertainty in Recycling Carbon Fiber Reinforced Composites
}

\author{
Arshyn MEIIRBEKOV ${ }^{\mathrm{a}}$, Essam SHEHAB $^{\mathrm{a}, 1}$ Akniyet AMANTAYEVA $^{\mathrm{a}}$, Aidar \\ SULEIMEN $^{\mathrm{a}}$, Serik TOKBOLAT ${ }^{\mathrm{b}}$, and Shoaib SARFRAZ ${ }^{\mathrm{c}}$ \\ ${ }^{a}$ Mechanical and Aerospace Engineering Department, School of Engineering and \\ Digital Sciences, Nazarbayev University, Nur-Sultan, Kazakhstan \\ ${ }^{\mathrm{b}}$ School of Architecture, Design and the Built Environment, Nottingham Trent \\ University, Nottingham, NG1 4FQ, UK \\ ${ }^{c}$ Manufacturing Department, School of Aerospace, Transport and Manufacturing, \\ Cranfield University, Cranfield, MK 43 OAL, UK
}

\begin{abstract}
Recycling of carbon fiber reinforced polymer composites (CFRPs) is a trending topic in the context of the current levels of CFRPs application in different industries and evolving environmental legislation and regulations. However, the recycling processes tend to be accompanied by various uncertainties leading to an increase of difficulties in evaluating them. This study aims to investigate the uncertainties that accompany the recycling of CFRPs by identifying, categorizing, and analysing their impacts. Four main categories such as technical (primary recycling process), recyclate pre-processing, supply chain, and market uncertainties were identified in this study and analysed in a wider context.
\end{abstract}

Keywords. Carbon Fiber Composites, Recycling, Uncertainty.

\section{Introduction}

Carbon fiber reinforced polymer composites (CFRPs) are widely used in different industries such as automotive, aerospace, wind turbine, sports equipment manufacturing etc. due to their outperforming characteristics compared to traditional materials (metals, alloys, and plastics) [1]. The global demand for CFRPs is projected to reach 194000 tons in the year 2022, which will indicate reaching the $12 \%$ annual growth rate from 2010 [1]. This aggressive growth in the application of CFRPs in the aforementioned industries presents an environmental challenge with the creation of waste in vast volumes such as the cut-offs during manufacturing and end-of-life products. The conventional composite waste disposal ways such as landfilling and incineration are no longer satisfactory due to their detrimental environmental impact and tightening legislation as stated by Directive 2008/98/EC in EU [2]. To address this issue, a number of recycling methods have been developed over the last 3 decades including thermal, chemical, and mechanical processes. The most developed and commonly used processes are mechanical recycling, pyrolysis, fluidized bed, and solvolysis processes [3]. Nevertheless, they still differ in terms of the levels of technology readiness which results in the raising of uncertainties that affect the perception of their effectiveness [2]. Moreover, the recycling of CFRPs

\footnotetext{
${ }^{1}$ Corresponding Author. essam.shehab@nu.edu.kz
} 
tends to be affected by other uncertainty factors not only at the process level but also at the market and supply chain scales. Thus, this work aims to identify, categorize, and analyze uncertainties pertinent to the CFRPs recycling processes by conducting a review of up-to-date literature in the field.

\section{Uncertainty in the recycling of CFRPs}

Even though some of the researchers may argue that risk and uncertainty are interchangeable concepts, this research adopts the following definitions: Uncertainty is "the indefiniteness of an event" [4]. Risk is the probability of loss (financial) from an unfavorable event. [4].

To understand and assess uncertainties, it is important to visualize the general process of waste recycling from the stage "recyclate" to "the recovered carbon fibers" (rCFs). Figure 1 illustrates the step-by-step process of recycling end-of-life CFRP waste.

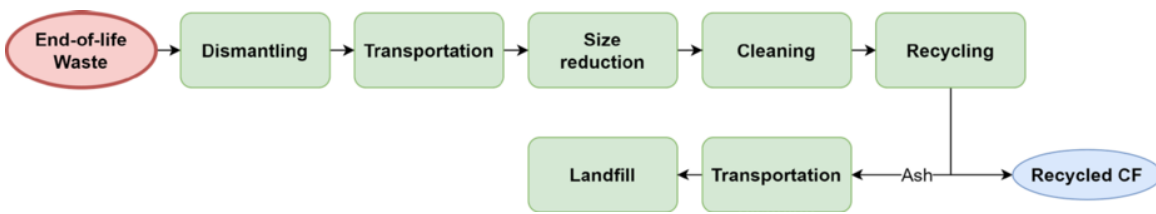

Figure 1. The general process chain in the recycling of CFRPs.

To identify uncertainties, the study adopted the narrative literature review method. As a result, 15 uncertainty factors were identified and classified into four major categories. Figure 2 presents a fishbone diagram indicating the uncertainty factors and their main categories. The selection of categories was defined based on the respective stages in the chain of recycling. The technical category is the combination of all uncertainties associated with the primary recycling processes. The market category, in turn, is related to the ambiguity of the recyclate market, whereas the supply chain-related uncertainty is tied to the concerns in waste supply and demand for rCFs.

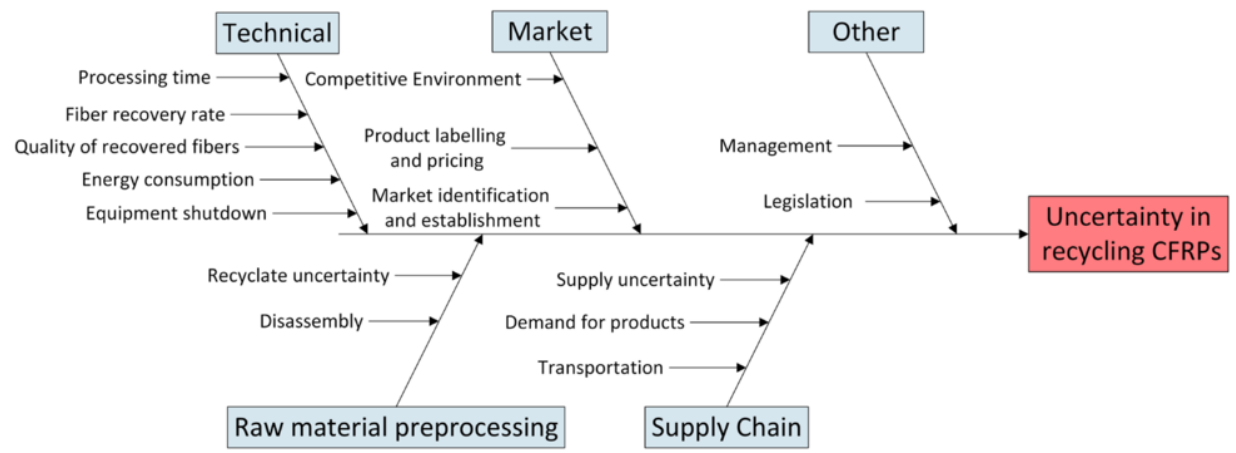

Figure 2. Uncertainty categories in the recycling of CFRPs

\subsection{Technical uncertainties}

Technical uncertainties arise during the primary recycling process. First of all, it should be noted that the fiber recovery rate is a critical parameter in recovering composite 
materials which predefine the viability of the process [5]. Mechanical recycling which is used to grind and mill composite waste into powder results in high losses; only $40 \%$ of carbon fiber present in CFRP is assumed to be recoverable [5]. On the other hand, the thermal methods including pyrolysis and fluidized bed process and chemical methods are reported to recover fully, though can still be accompanied by some minor losses [2]. This will be resulting in considerable uncertainty during mass-scale recycling affecting the final output of the process.

The quality of rCFs is another uncertainty factor in the recycling of CFRPs [2]. Table 1 represents substantial variation in the retention rate of mechanical properties and qualities of rCFs. Mechanical properties seem to retain differently depending on the types of the applied recycling process. However, it should be noted that this variability seems to be present even within the same process most likely due to its conditions and parameters. The best preservation of mechanical properties and clean surfaces is possible to achieve using chemical methods [6]. In contrast, rCFs from pyrolysis tend to have residual char on the fiber's surface. The fluidized bed process, in turn, retains only $80 \%$ of tensile strength due to high temperature and attrition resulted from sand particles [7]. All the described approaches except solvolysis reduce the length of fibers to some extent depending on the equipment size [2].

Table 1. The retention rate of mechanical properties of rCFs compared to virgin fibers for different techniques of CFRP recycling.

\begin{tabular}{|c|c|c|}
\hline $\begin{array}{l}\text { Recycling } \\
\text { Technique }\end{array}$ & rCF qualities (surface, length) & $\begin{array}{l}\text { Retention rate of } \\
\text { tensile strength }\end{array}$ \\
\hline Mechanical recycling & Short milled fibers, powders, length degraded [2] & $40-50 \%[8]$ \\
\hline Pyrolysis & $\begin{array}{l}\text { Fluffy, discontinuous, residual char left on the } \\
\text { surface [2] }\end{array}$ & $\begin{array}{r}15-98 \%[2] \\
90 \text { to } 100 \%[9]\end{array}$ \\
\hline Fluidized bed process & Length degraded, fluffy $[10]$ & $\begin{array}{r}10-75 \%[11] \\
82 \%[7]\end{array}$ \\
\hline Solvolysis & Clean fibers with no char, length not degraded [9] & $94-98 \%[6]$ \\
\hline
\end{tabular}

Energy consumption is one of the key reasons why recycling CFRPs with consequent manufacturing using rCFs might seem more attractive in contrast to manufacturing virgin carbon fibers. According to Giorgini et al. [3], the production of virgin fibers requires $183-286 \mathrm{MJ} / \mathrm{kg}$ which is multiple times higher than in other recycling processes. Nevertheless, the data on energy use inputs tend to vary significantly, thus, generating uncertainty if large projects are concerned. Table 2 represents recycling processes with respective energy consumption rates and the variations are remarkable. It is important to mention that energy consumption depends on other parameters such as temperature, feed rate, processing time. However, there is a gap between different studies which creates uncertainty in terms of this parameter.

Table 2. Energy consumption rates for recycling techniques.

\begin{tabular}{ccc}
\hline Recycling Technique & Energy consumption $(\mathbf{M J} / \mathbf{k g})$ & References \\
\hline Mechanical recycling & $0.27(150 \mathrm{~kg} / \mathrm{h})$ & {$[12]$} \\
& $2.03(10 \mathrm{~kg} / \mathrm{h})$ & {$[13]$} \\
\hline Pyrolysis & 2.8 & {$[14]$} \\
\hline Fluidized bed process & 30 & {$[15]$} \\
\hline Solvolysis & $6\left(\right.$ at $12 \mathrm{~kg} / \mathrm{h}^{*} \mathrm{~m}^{2}$ feed rate $)$ & {$[16]$} \\
& $63-91$ & {$[17]$} \\
\hline
\end{tabular}

There are other technical uncertainties that are pertinent to any industrial process, for example, processing time, equipment breakdown, outdated technologies, etc. These are not considered separately in this work due to their commonality. 


\subsection{Market-related uncertainties}

The range of rCF products varies extensively based on the sizes and mechanical properties. The closest products after recycling are the chopped mats, non-woven mats, discontinuous short and long fibers [2]. However, there is no consistent labeling of products based on the common parameters of the products which is a challenge and uncertainty at the same time. The pricing is another issue due to the unavailability of consistent rates for certain types of $\mathrm{rCF}$ products. Although the companies such as ELG Carbon fibre and Zoltek produce their labels for the recycled products (such as, for example, Carbiso MT, Carbiso MF, Zoltek Type, etc), there is still a diverging impact to the market of rCF products unless the products are standardized and labelled equally.

At present, the investigation of effective applications of rCFs is an important factor that will most likely define the overall success of the composite recycling industry. Until now, the market establishment of rCF in a foreseeable future is still questionable.

\subsection{Raw material preprocessing-related uncertainties.}

CFRP recycling industry uses end-of-life or manufacturing waste from various other industries as a feedstock. Half of the CFRP manufacturing waste is reported to be generated from pattern cutting and is made of woven prepreg which can be delivered to a recycling plant in varying forms and shapes [18]. For instance, it can be delivered in the form of recently manufactured, sticky and knotty material, or hard, a compressed package of old, cured scrap [18]. There is a wide range of CFRP classifications which leads to creating uncertainties both for waste producers and recyclers around recyclability and cost. Therefore, it is imperative to understand not only the mechanical properties of virgin materials but also their chemical structure. In CFRPs, the polymer matrix is reinforced by carbon fibers either in continuous or discontinuous forms [19]. Common matrix materials for manufacturing CFRPs are thermosets (e.g. epoxy, polyester, thermoplastics) which are reinforced by carbon fiber of different percentages (e.g. 30, 50, 70). CFRPs can also be classified based on the level of modulus (e.g. ultrahigh, high, intermediate, etc.) and manufacturing method (PAN-based, pitch-based) [20]. Moreover, manufacturing composites for different purposes require adding other materials such as metal and ceramic pieces, polymeric barrier films, and top coatings [19]. This typically tends to lead to a divergence of resultant recycled material quality. Another challenge commonly faced by the recyclers is linked to CFRPs waste which is delivered without a specified matrix resin, thus, adding an extra level of uncertainty. This requires a preliminary analysis to assess the recyclability of the material which, in turn, adds an extra cost for the transportation of waste samples.

Prior to recycling CFRPs, the waste material needs to be collected, dismantled, classified, separated from scrap material followed by size reduction and cleaning. These preprocessing steps are not universal for all types of CFRP waste as it varies from one recycling technique to another. For example, the mechanical recycling method requires steps such as size reduction, cut, and shred [5], while in the pyrolysis process only sizing is required [10]. Waste contamination is a key issue during the recycling process, in which different contamination levels require different treatments. Besides, CFRP materials from aerospace and wind turbine manufacturing industries require dismantling works to be carried out, thus, increasing the labor costs, especially if hand sorting is required. For example, hand sorting alone might cost up to 2 USD per $\mathrm{kg}$ of prepreg scrap [18]. To lower the uncertainty level associated with the costs, there is a necessity 
for developing international standards and regulations for the dismantling and decommissioning of wind turbine components as well as airplanes.

\subsection{Supply chain-related uncertainties}

Another noteworthy uncertainty source that requires consideration is related to the supply of raw materials for recycling plants. The projected amount of scrap from CFRP part made today can be estimated for the next 20-30 years, however, it is hard to assess the amount of manufacturing waste generated at present. In order to ensure financial viability and attracting investments, the CFRP recycling industry needs to have a continuous supply of recyclable composite material [19]. At present, the major carbon fiber waste source is considered to be the aerospace industry, however, aircraft original equipment manufacturers (OEMs) might establish in-house recycling rather than supplying the commercial CFRP recyclers [21]. There is a challenge to match polymer types to a particular application if external suppliers are involved.

On the other hand, there is uncertainty related to the demand for recycled fibers. There is a wide range of shapes of recycled products that can be converted, for example, to ready products or used for concrete reinforcement [22]. However, the application of rCFs for these purposes is still in the scope of $R \& D$ projects [21]. Carbon fiber recycling technologies related research aim to narrow the gap between high demand and low production capacity of virgin CFs, however, they could be replaced by recycled fibers in very limited applications [23]. Therefore, uncertainties related to the demand require establishing additional ways of application of secondary fibers as well as widening the industry range that can benefit from rCFs.

Finally, the other source of uncertainty that has not been previously discussed is related to the legislation for recycling. For example, the classification of pyrolysis for recycling carbon fiber composites has to be distinguished from traditional pyrolysis [24]. The potential privileges granted by governments for recycling instead of landfilling are still ambiguous and vary from state to state, again, resulting in uncertainty [25].

\section{Conclusions}

This study is conducted to identify and categorize uncertainties in the current CFRP recycling industry. The identified categories are technical, market-related, raw material pre-processing, and supply chain-related uncertainties. Overall, the recycling industry needs to standardize the process parameters and recycled product properties, ensure consistent waste supply, and establish a stable rCF market. To bring the CFRP recycling industry to the next level and advance it to a larger scale it is important to reduce the impact of uncertainties pertinent to almost every process. It is recommended to establish a knowledge base system to be able to share relevant data between technology owners, scrap holders, and demand generators. All actors need to fully collaborate and understand each other's requirements to limit the impact of uncertainties. This study is a part of an ongoing project focusing on the development of a framework for quantifying the impact of uncertainty factors on the costs of CFRP recycling. 


\section{Acknowledgments}

The authors would like to thank Nazarbayev University for funding this article under the Faculty Development Competitive Research Grant Program (FCDRGP) Grant No.110119FD4524.

\section{References}

[1] M. Sauer, M. Kuhnel, and E. Witten, "Composites Market Report 2017-Market developments, trends, outlook and challenges," 2017.

[2] J. Zhang, V. S. Chevali, H. Wang, and C. Wang, "Current status of carbon fibre and carbon fibre composites recycling," Compos. Part B, vol. 193, no. December 2019, p. 108053, 2020.

[3] L. Giorgini, T. Benelli, G. Brancolini, and L. Mazzocchetti, "Recycling of carbon fiber reinforced composite waste to close their life cycle in a cradle-to-cradle approach," Curr. Opin. Green Sustain. Chem., vol. 26, p. 100368, Dec. 2020.

[4] G. Rajkumar and K. Alagarsamy, "THE MAJOR UNCERTAINTY FACTORS AFFECTING IN SOFTWARE COST ESTIMATION,” vol. 4, no. June, pp. 419-424, 2013.

[5] X. Li, R. Bai, and J. Mckechnie, "Environmental and fi nancial performance of mechanical recycling of carbon fi bre reinforced polymers and comparison with conventional disposal routes," J. Clean. Prod., vol. 127, no. 2016, pp. 451-460, 2016.

[6] L. Henry, A. Schneller, J. Doerfler, W. M. Mueller, C. Aymonier, and S. Horn, "Semi-continuous flow recycling method for carbon fibre reinforced thermoset polymers by near- and supercritical solvolysis," Polym. Degrad. Stab., vol. 133, pp. 264-274, 2016.

[7] S. J. Pickering et al., "DEVELOPMENTS IN THE FLUIDISED BED PROCESS FOR FIBRE RECOVERY FROM THERMOSET COMPOSITES,” no. October 2015, 2016.

[8] H. Li and K. Englund, "Recycling of carbon fiber-reinforced thermoplastic composite wastes from the aerospace industry," 2016.

[9] S. Job, G. Leeke, P. T. Mativenga, G. Oliveux, S. Pickering, and N. A. Shuaib, "COMPOSITES RECYCLING : Where are we now ?," 2016.

[10] S. J. Pickering, "Recycling technologies for thermoset composite materials-current status," Compos. Part A Appl. Sci. Manuf., vol. 37, no. 8, pp. 1206-1215, 2006.

[11] J. Zhu, P. Chen, M. Su, C. Pei, and F. Xing, "Recycling of carbon fi bre reinforced plastics by degradation of epoxy resin $\dagger, ” 2019$.

[12] J. Howarth, S. S. R. Mareddy, and P. T. Mativenga, "Energy intensity and environmental analysis of mechanical recycling of carbon fibre composite,"J. Clean. Prod., vol. 81, pp. 46-50, 2014.

[13] Y. S. Song, J. R. Youn, and T. G. Gutowski, "Composites : Part A Life cycle energy analysis of fiberreinforced composites," Compos. Part A, vol. 40, no. 8, pp. 1257-1265, 2009.

[14] R. A. Witik, R. Teuscher, V. Michaud, C. Ludwig, and J. A. E. Månson, "Carbon fibre reinforced composite waste: An environmental assessment of recycling, energy recovery and landfilling," Compos. Part A Appl. Sci. Manuf., 2013.

[15] F. Meng, McKechnie, Jon, T. Turner, and S. J. Pickering, "Energy and environmental assessment and reuse of fluidised bed recycled carbon fibres," Compos. Part A Appl. Sci. Manuf., vol. 100, pp. 206-214, 2017.

[16] K. Shibata and M. Nakagawa, “CFRP Recycling Technology Using Depolymerization under Ordinary Pressure," 2014.

[17] M. J. Keith and G. A. Leeke, "OPTIMISATION OF SOLVOLYSIS FOR RECYCLING CARBON FIBRE REINFORCED COMPOSITES,” no. June, pp. 26-30, 2016.

[18] V. P. McConnell, "Launching the carbon fibre recycling industry," Reinf. Plast., 54(2), 33-37, 2010.

[19] E. Asmatulu, J. Twomey, and M. Overcash, "Recycling of fiber-reinforced composites and direct structural composite recycling concept," J. Compos. Mater., vol. 48, no. 5, pp. 593-608, 2014.

[20] D. Kopeliovich, "Carbon Fiber Reinforced Polymer Composites," SubsTech, 2012. .

[21] S. Francis, "The state of recycled carbon fiber," Composites World, 2020.

[22] K. Ogi, T. Shinoda, and M. Mizui, "Strength in concrete reinforced with recycled CFRP pieces," Compos. Part A Appl. Sci. Manuf., vol. 36, no. 7, pp. 893-902, Jul. 2005.

[23] F. Meng, J. Mckechnie, and S. . Pickering, "An assessment of financial viability of recycled carbon fibre in automotive applications," Compos. Part A Appl. Sci. Manuf., vol. 109,pp. 207-220, 2018.

[24] S. H. Alsop, "Pyrolysis off-gas processing.," in SAMPE'09, 2009.

[25] S. Line, "Commercialisation of the carbon fibre recycling process.," in Carbon Fibre Recycling and Reuse 2009 Conference, 2009. 